\title{
Chemical Probes for Water-Oxidation: Synthetic Manganese Complexes in Photoactivation of Water Splitting Complex and as Exogenous Electron Donors to Photosystem II
}

\author{
Gábor Bernát ${ }^{\mathrm{a} \S}$, Subhash Padhye ${ }^{\mathrm{b}}$, Csilla Barta ${ }^{\mathrm{a}}$, László Kovács ${ }^{\mathrm{a}}$ and \\ Sándor Demeter ${ }^{\mathrm{a},}{ }^{*}$ \\ a Institute of Plant Biology, Biological Research Center, Hungarian Academy of Sciences, \\ P. O. Box 521, H-6701 Szeged, Hungary. Fax: +36-62-433-434. \\ E-mail: tudor@nucleus.szbk.u-szeged.hu \\ b Department of Chemistry, University of Poona, Pune-411007, India \\ $\S$ Present address: Biochemistry, Center for Chemistry and Chemical Engineering, Lund \\ University, P. O. Box 124, S-221 00 Lund, Sweden \\ * Author for correspondence and reprint request
}

Z. Naturforsch. 56c, 755-766 (2001); received April 9/May 28, 2001

Photosystem II, Water Splitting Complex, Synthetic Manganese Complexes

Photoactivation of the water splitting enzyme was performed with 13 different synthetic manganese complexes and characterized by oxygen evolution yield, thermoluminescence and chlorophyll fluorescence induction kinetics. The efficiency of different compounds in photoactivation correlated with the rate of linear electron transport in the presence of these compounds. The organic ligands, associated with the manganese ions, do not prevent the photoactivation of the water splitting complex (WOC). Photoactivation with different manganese complexes depended on the number of the Mn-ions in the complex, their valence state and the nature of their donor atoms. The most efficient restorations were achieved by using tetrameric complexes having a dimer+dimer structure, complexes containing $\mathrm{Mn}$ (II) ions, and having 4-6 oxygen and $0-2$ nitrogen atoms as donor atoms. Further, the effectiveness of photoactivation depended largely on the structure of the complexes. Our data support the notion that WOC in intact thylakoids requires the cooperation and well determined arrangement of all four manganese ions, and argue against the hypothesis that two manganese ions are sufficient for water splitting. Photoactivation by some complexes led to anomalous flashoxygen patterns, which are explained by a modified/perturbed water splitting complex.

\begin{abstract}
Abbreviations: Chl, chlorophyll; DCMU, 3-(3',4'-dichlorophenyl)-1,1-dimethylurea; EPR, electron paramagnetic resonance; $F_{\mathrm{m}}$, maximal fluorescence; $F_{\mathrm{o}}$, initial fluorescence; $F_{v}$, maximal variable fluorescence; $F_{v}{ }_{v}$, increase of maximal variable fluorescence after photoactivation; $\mathrm{L}_{1}$, salicylaldoxime; $\mathrm{L}_{1}{ }^{*}$, deprotonated $\mathrm{L}_{1} ; \mathrm{L}_{2}=\mathrm{L}_{3}, 3,5$-di-tertbutyl-1,2-benzoquinone monoxime; $\mathrm{L}_{4}, 2$-hydroxy-1,4naphthoquinone; $L_{5}, 2$-hydroxy-3-methyl-1,4-naphthoquinone (phthiocol); $\mathrm{L}_{6}$, acetylphthiocolmonoxime; $\mathrm{L}_{7}$, propionylphthiocolmonoxime; $\mathrm{L}_{8}, 1,10$-phenanthroline; $\mathrm{L}_{9}, 3$ [(((2'-pyridyl)methyl)imino)methyl]benzene-1,2-diol; $\mathrm{L}_{10}$, 3-[((2-(2'-pyridyl)ethyl)imino)methyl]benzene-1,2-diol;

$\mathrm{L}_{11}$, 3-[((2-(hydroxymethyl)phenyl)imino)methyl]benzene1,2-diol; $\mathrm{L}_{12}, \quad 3$-[((2'-benzimidazolyl)methyl)imino)methyl]benzene-1,2-diol; $\mathrm{L}_{13}, 3-\left[\left(\left(2^{\prime}\right.\right.\right.$-pyridyl)hydrazono)methyl]benzene-1,2-diol; $\mathrm{M}-1\left(\mathrm{~L}_{2}\right), \mathrm{M}-2\left(\mathrm{~L}_{\mathrm{x}}\right)(\mathrm{x}=3-7), \mathrm{M}-3-$ $\left(\mathrm{L}_{8}\right), \mathrm{M}-4\left(\mathrm{~L}_{\mathrm{y}}\right)(\mathrm{y}=1,9-13)$, synthetic mono-, bi-, tri- and tetranuclear manganese complexes, respectively; MES, 4morpholinoethanesulfonic acid; PS II, photosystem II; Qband, thermoluminescence band associated with $S_{2} Q_{A}$. charge recombination; $Q_{A}$ and $Q_{B}$, primary and secondary quinone acceptors of PS II, respectively; TL, thermoluminescence; WOC, water splitting complex; $\mathrm{Y}_{\mathrm{D}}$ and $\mathrm{Y}_{\mathrm{Z}}$, redox active tyrosine- 161 of $D_{2}$ and redox active tyrosine161 of $D_{1}$ reaction center protein of PS II, respectively.
\end{abstract}

\section{Introduction}

The catalytic reaction of oxygen evolution, represented by the overall equation $2 \mathrm{H}_{2} \mathrm{O} \rightarrow \mathrm{O}_{2}+$ $4 \mathrm{H}^{+}+4 \mathrm{e}^{-}$, takes place at the four manganese-containing water splitting complex (WOC) located at the donor side of photosystem II (PS II) (for reviews, see Debus, 1992; Britt, 1996; Robblee et al., 2001; Nugent et al., 2001; Renger, 2001; and accompanying reviews in the same issue). Evolution of one molecule of oxygen is preceded by accumulation of four positive charges at the level of WOC, generated by four sequential photoactions of the PS II reaction center. Thus the WOC exists in five different in vivo redox states, designated from $\mathrm{S}_{0}$ to $\mathrm{S}_{4}$. Mechanism of water oxidation and many structural detail of the manganese complex is unknown.

One of the methods in studying the WOC is the light-dependent assembly of the manganese com- 
plex, so called photoactivation. Such experiments were carried out on a wide variety of experimental objects from PS II particles to intact plants (Tamura and Cheniae, 1987; Kamachi et al., 1994). During photoactivation two light-dependent events $\left(\mathrm{Mn}^{2+} \rightarrow \mathrm{Mn}^{3+}\right.$ oxidations) are linked with a light-independent step (ligation of the second manganese) (Tamura and Cheniae, 1987; Miller and Brudvig, 1990). Recently, Ananyev and his coworkers have carried out intensive quantitative studies on the kinetics of photoactivation and could construct an impressive model for this procedure (see Ananyev et al., 2001; and references therein). This implies detailed interpretation of the first steps and intermediates as well as the elucidation of the role of the $\mathrm{Ca}^{2+}$ ion during the photoactivation (Chen et al., 1995). Reactivation of the water oxidation requires $\mathrm{Cl}^{-}$- (Miyao and Inoue, 1991a) and according to recent data (reviewed by Klimov and Baranov, 2001) bicarbonate-ions. The reactivation of WOC is probably accompanied with structural rearrangement(s). The observation, that photoactivation involves a downshift of the redox potential of the primary quinone acceptor, $\mathrm{Q}_{\mathrm{A}}$ (Johnson et al., 1995) supports this suggestion.

The bioinorganic approach at the research of manganese-containing enzymes is to model them by structural analogs of synthetic mono-, bi-, triand tetranuclear manganese complexes (reviewed by Wieghardt, 1989; Law et al., 1999). In these studies certain physical properties of the structural analogs and native enzymes are compared (e.g. Wells et al., 1993; Schäfer et al., 1998). It is obvious to probe synthetic manganese complexes in photoactivation experiments. Such kind of experiments were carried out by Allakhverdiev et al. (1994a, 1999) by using binuclear and mononuclear manganese complexes, respectively. According to their observations these complexes were more effective in photoactivation of manganese-depleted PS II particles than $\mathrm{MnCl}_{2}$ (Allakhverdiev et al., 1994a,b, 1999). Moreover, exogenous electron donation capability of their binuclear $\mathrm{Mn}$ (III) complexes exceeded the value belonging to $\mathrm{MnCl}_{2}$. In the present work we have compared the effectiveness of thirteen synthetic complexes not examined in photoactivation experiments before (one mono-, five bi-, one tri- and six tetranuclear complexes) with that of $\mathrm{MnCl}_{2}$ in both types of experi- ments mentioned above. Tri- and tetranuclear manganese complexes have not probed in photoactivation yet.

\section{Materials and Methods}

\section{Sample preparation}

Oxygen-evolving thylakoid membranes were isolated from spinach, as described by Völker et al. (1985) and stored at $77 \mathrm{~K}$ in a buffer containing $0.4 \mathrm{~m}$ sucrose, $15 \mathrm{~mm} \mathrm{NaCl}, 5 \mathrm{~mm} \mathrm{MgCl}_{2}$ and $20 \mathrm{~mm}$ MES $(\mathrm{pH}=6.5)$ (= buffer A). Manganese-depleted PS II particles were isolated by the method of Tamura and Cheniae (1987) in buffer A in the presence of $5 \mathrm{mM} \mathrm{NH}_{2} \mathrm{OH}$, followed by washing twice in $\mathrm{NH}_{2} \mathrm{OH}$-free medium. In photoactivation experiments the $\mathrm{NH}_{2} \mathrm{OH}$-treated PS II particles were suspended in a buffer containing $20 \mathrm{~mm} \mathrm{CaCl}_{2}$, $110 \mathrm{~mm} \mathrm{NaCl}, 0.4 \mathrm{~m}$ sucrose and $20 \mathrm{~mm}$ MES $(\mathrm{pH}=6.5)(=$ buffer $\mathrm{B})$ and $100,50,33$ or $25 \mu \mathrm{M}$ Mn mononuclear, binuclear, trinuclear or tetranuclear complexes, respectively, in the presence of $10 \mu \mathrm{M}$ 2,6-dichlorophenol indophenol (DCIP) as electron acceptor $([\mathrm{Chl}]=125 \mu \mathrm{g} / \mathrm{ml})$. The suspension was illuminated by twenty short cycles $(20 \mathrm{~s}$, separated by $20 \mathrm{~s}$ of dark) of weak $\left(1 \mathrm{~W} / \mathrm{m}^{2}\right)$ red light of 102 L LED lamp of PAM chlorophyll fluorometer (Walz, Effeltrich, Germany; peak wavelength: $650 \mathrm{~nm}$, half bandwidth: $25 \mathrm{~nm}$ ) at room temperature. After illumination the samples were centrifuged and suspended in buffer B.

\section{Measurements of photosynthetic activity}

The photosynthetic oxygen evolution induced by continuous illumination was measured with a Clark-type electrode (Hansatech, Norfolk, UK) at room temperature at saturating light intensity $([\mathrm{Chl}]=50 \mu \mathrm{g} / 1.5 \mathrm{ml})$. Flash-induced oxygen evolution was monitored with a home-built Joliot-type electrode $([\mathrm{Chl}]=10 \mu \mathrm{g} / 100 \mu \mathrm{l})$. The thermoluminescence (TL) profiles were measured as described in Demeter et al. (1985). The dark-adapted samples were excited at $-40^{\circ} \mathrm{C}$ with continuous white light; the heating rate was $20^{\circ} \mathrm{C} / \mathrm{min}$. The fluorescence measurements were carried out on a PAM-101 chlorophyll fluorometer (Walz) at $25 \mu \mathrm{g} /$ $\mathrm{ml} \mathrm{Chl-concentration.} \mathrm{At} \mathrm{the} \mathrm{analysis} \mathrm{of} \mathrm{data} \mathrm{the}$ average of 3 independent measurements were taken. 


\section{Synthetic manganese complexes}

$\left[\mathrm{Mn}^{\mathrm{II}}\left(\mathrm{L}_{2}\right) \mathrm{Cl}_{2}\left(\mathrm{H}_{2} \mathrm{O}\right)_{2}\right]$ complex $\left[=\mathrm{M}-1\left(\mathrm{~L}_{2}\right)\right]$ was synthesized by reacting $\mathrm{MnCl}_{2} \cdot 2 \mathrm{H}_{2} \mathrm{O} 3,5$-di $($ tertbutyl)-1,2-benzoquinone monoxime $\left(=\mathrm{L}_{2}=\mathrm{L}_{3}\right)$ in aqueous ethanolic solution in 1:2 molar ratio for $3 \mathrm{hrs}$ when the green crystalline compound was precipitated out. It was washed with aqueous ethanol and dried in vacuum while the reaction of $\mathrm{L}_{2}=$ $\mathrm{L}_{3}$ with $\mathrm{Mn}(\mathrm{Oac})_{2} \cdot 2 \mathrm{H}_{2} \mathrm{O}$ in 1:2 molar ratio yielded the green compound $\left[\mathrm{Mn}^{\mathrm{II}, \mathrm{II}}\left(\mathrm{L}_{3}\right)(\mathrm{Oac})_{2}\right](\mathrm{Oac})_{2}$ symbolised as $\mathrm{M}-2\left(\mathrm{~L}_{3}\right)$.

The interaction of $\mathrm{Mn}(\mathrm{Oac}) 2 \cdot 2 \mathrm{H}_{2} \mathrm{O}$ with 2-hydroxy-1,4-naphthoquinone $\left(=\mathrm{L}_{4}\right)$ in $1: 2$ metal to ligand ratio under nitrogen atmosphere in methanol-water medium yielded the compound $\left[\mathrm{Mn}\left(\mathrm{L}_{4}\right)_{2}\left(\mathrm{H}_{2} \mathrm{O}\right)_{2}\right]$. Replacement of the two water molecules by 1,10 -phenanthroline $\left(=\mathrm{L}_{8}\right)$ produced the $\left[\mathrm{Mn}^{\mathrm{II}, \mathrm{II}}\left(\mathrm{L}_{4}\right)\left(\mathrm{L}_{8}\right)\right]_{2}$ complex $\left[=\mathrm{M}-2\left(\mathrm{~L}_{4}\right)\right]$. $\mathrm{Na}_{2}\left[\mathrm{Mn}^{\mathrm{II}, \mathrm{II}}\left(\mathrm{L}_{5}\right)(\mathrm{Oac})_{2}\right]_{2}\left(\mathrm{H}_{2} \mathrm{O}\right)_{2}, \quad\left[\mathrm{Mn}^{\mathrm{II}, \mathrm{III}}\left(\mathrm{L}_{6}\right)_{2}\right]_{2}$ and $\left[\mathrm{Mn}^{\mathrm{II}, \mathrm{III}}\left(\mathrm{L}_{7}\right)_{2}\right]_{2}$ complexes $\left[=\mathrm{M}-2\left(\mathrm{~L}_{5}\right), \mathrm{M}-\right.$ $2\left(\mathrm{~L}_{6}\right)$ and $\mathrm{M}-2\left(\mathrm{~L}_{7}\right)$, respectively] were synthesized as per literature procedures (Padhye et al., 1978). $\left[\mathrm{Mn}^{\mathrm{III}} \mathrm{O}_{4}\left(\mathrm{~L}_{8}\right)_{4}\left(\mathrm{H}_{2} \mathrm{O}\right)_{2}\right]\left(\mathrm{NO}_{3}\right)_{4} \cdot 2.5 \mathrm{H}_{2} \mathrm{O}$ complex [M-3 $\left.\left(\mathrm{L}_{8}\right)\right]$ was synthesized according to Reddy et al. (1996).

$\left[\mathrm{Mn}^{\mathrm{III}}{ }_{4}\left(\mathrm{~L}_{1}\right)\left(\mathrm{L}_{1}{ }^{*}\right)\right]_{4} \cdot 3 \mathrm{CHCl}_{3}$ complex $\left[=\mathrm{M}-3\left(\mathrm{~L}_{8}\right)\right]$ was synthesized as described by Aggarwal et al. (1984). $\left[\mathrm{Mn}_{2}{ }_{2} \mathrm{~L}_{\mathrm{x}}(\mathrm{OAc})_{2}(\mathrm{MeOH})\right]_{2} \quad(\mathrm{x}=9-13)$ tetranuclear complexes $\left[=\mathrm{M}-4\left(\mathrm{~L}_{\mathrm{x}}\right)\right]$ were synthesized following a general procedure reported by Theil et al. (1997).

The purity of the synthesized manganese compounds was checked by comparing their analytical and spectral profiles with the authentic samples.

\section{Results and Discussion}

The electron donation capacity of $\mathrm{MnCl}_{2}$ and thirteen manganese complexes was investigated in manganese-depleted spinach thylakoid membranes by fluorescence induction measurements. Addition of complexes was performed in the dark therefore photoactivation of the samples could be excluded. The dissociation of $\mathrm{MnCl}_{2}$ and the complexes was compared in aqueous solution by EPR measurements. The amplitude of the six-line EPR signal exhibited by the complexes was smaller with several orders of magnitude than for $\mathrm{MnCl}_{2}$ (data not shown). Consequently, these complexes can be considered fairly stable in solution.
Fig. $1 \mathrm{~A}$ shows the effects of $\mathrm{MnCl}_{2}$ on the fluorescence induction curves of manganese-depleted thylakoid membranes. After turning on the measuring beam (thin arrow) the fluorescence promptly jumped up to its initial level, $F_{\mathrm{o}}$. The yield elevated to the maximum level, $\mathrm{F}_{\mathrm{m}}$ after switching on the actinic beam (thick arrow). After manganese depletion the $F_{m}$ value significantly decreased in comparison with the control while the $\mathrm{F}_{\mathrm{o}}$-level did not change (Fig. 1A, curve 1 and 2) similarly as
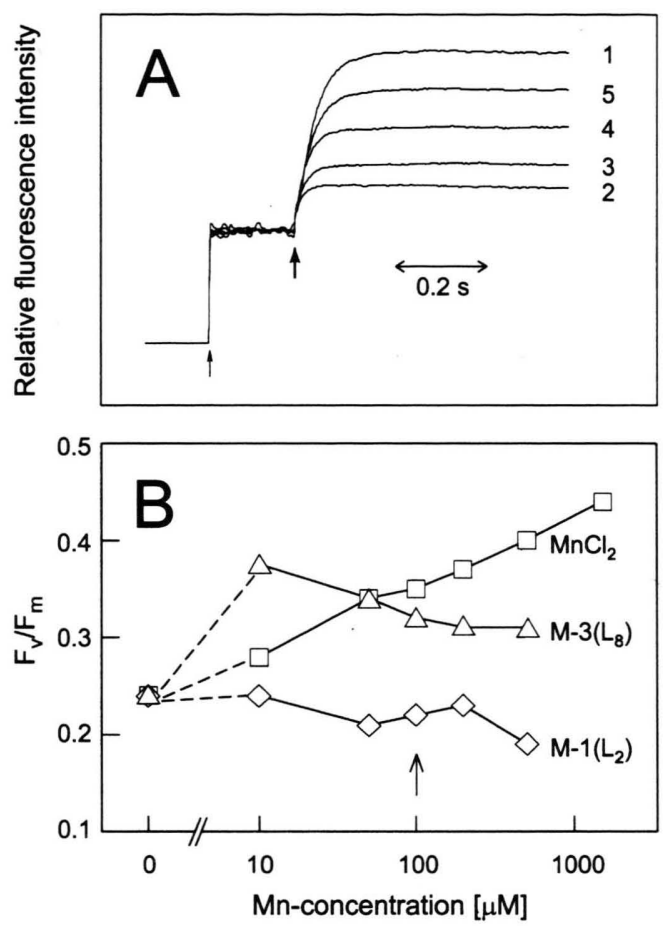

Fig. 1. Effect of $\mathrm{MnCl}_{2}, \mathrm{M}-1\left(\mathrm{~L}_{2}\right)$, a synthetic mono-, and $\mathrm{M}-3\left(\mathrm{~L}_{8}\right)$, a synthetic trinuclear manganese complex, respectively, on the $F_{v} / F_{m}$ ratio of manganese-depleted thylakoid membranes. (A) Effect of depletion and subsequent addition of manganese on the fluorescence induction curves of thylakoid membranes: (1) control; (2) manganese-depleted membranes without addition; manganese-depleted membranes with addition of (3) $10 \mu \mathrm{M}$; (4) $200 \mu \mathrm{M}$ and (5) $5000 \mu \mathrm{M} \mathrm{MnCl}_{2}$. Thin and thick arrows indicate the onset of the measuring- $\left(0.1 \mathrm{~W} / \mathrm{m}^{2}\right)$ and actinic beam $\left(10 \mathrm{~W} / \mathrm{m}^{2}\right)$, respectively. Simultaneously with the onset of actinic light the signal to noise ratio of the signal was decreased by modulation of the measuring light with $100 \mathrm{kHz}$. (B) Effect of the probed mononuclear and trinuclear manganese complexes on the normalized maximal variable fluorescence of manganese-depleted thylakoid membranes. Squares, diamonds and triangles represent the values belonging to $\mathrm{MnCl}_{2}$, $\mathrm{M}-1\left(\mathrm{~L}_{2}\right)$ and $\mathrm{M}-3\left(\mathrm{~L}_{8}\right)$, respectively. The arrow indicates the applied concentration in the case of photoactivation. 
observed by Klimov et al. (1982) and Allakhverdiev et al. (1994a, 1999). The remaining part of variable fluorescence $\left(\mathrm{F}_{\mathrm{v}}=\mathrm{F}_{\mathrm{m}}-\mathrm{F}_{\mathrm{o}}\right)$ is probably associated with electron transport from $\mathrm{Y}_{\mathrm{Z}}$ and (to lesser extent) cytochrome $b_{559}$ and $\mathrm{Y}_{\mathrm{D}}$ (Magnuson et al., 1999). Addition of $10 \mu \mathrm{M} \mathrm{MnCl}_{2}$ (Fig. 1A, curve 3) induced a significant increase in the fluorescence level in agreement with Klimov et al., (1982) and Allakhverdiev et al. (1994a). Increasing amount of added $\mathrm{MnCl}_{2}$ (Fig. 1A, curve 4,5) resulted in a further gradual enhancement in the $F_{v}$ value due to larger probability of electron donation.

The effect of manganese compounds was checked in manganese-containing membranes (not shown). Addition of increasing concentration of $\mathrm{MnCl}_{2}(10-5000 \mu \mathrm{M})$ did not cause any alteration in the fluorescence yield. On the other hand the synthetic manganese complexes slightly decreased the $F_{o}$ and $F_{m}$ level but the $F_{v} / F_{m}$ ratio $\left(\mathrm{F}_{\mathrm{v}} / \mathrm{F}_{\mathrm{m}} \approx 0.67\right)$ remained constant. We assume that the decrease of fluorescence yield is caused by light-absorption of the ligands and lowering of the light-harvesting capability of the chlorophyll antenna system.

The concentration dependence of $F_{v} / F_{m}$ in manganese-depleted samples reactivated with monoand trinuclear manganese complexes is shown in Fig. 1B. Similarly to $\mathrm{MnCl}_{2}$, equimolar amounts of the trinuclear complex, $\mathrm{M}-3\left(\mathrm{~L}_{8}\right)$ also induced an enhancement in the $F_{v} / F_{m}$ ratio, whereas the applied mononuclear complex, $\mathrm{M}-1\left(\mathrm{~L}_{2}\right)$ did not (Fig. 1B). It means that, from these two complexes, that one $\left[M-3\left(L_{8}\right)\right]$ has the better electron donation capability to PS II in which Mn ions exist at higher $(+3)$ valence state, has larger size and contains a ligand, 1,10-phenanthroline $\left(=\mathrm{L}_{8}\right)$, which is a well-known inhibitor to PS II. The data concerning the Mn valence state supports the findings that $\mathrm{Mn}$ (III) containing complexes also can donate electron to PS II (Allakhverdiev et al., 1994a). According to our present data this capability depends less on the size of the complex than expected. Due to the action site of 1,10-phenanthroline at the non-heme iron of PS II between $\mathrm{Q}_{\mathrm{A}}$ and $\mathrm{Q}_{\mathrm{B}}$, the primary and secondary quinone acceptor of PS II, respectively (Klimov et al., 1980), it does not influence the restoration of variable fluorescence indicating the reduction of $\mathrm{Q}_{\mathrm{A}}$. Further, $\mathrm{L}_{8}$ is stable bound to $\mathrm{Mn}$-ions, thus probably unable to interact with non-heme iron. Al- though these complexes did not inhibit the $F_{v} / F_{m}$ ratio of fluorescence in manganese-containing thylakoid membranes, at high concentrations they induced some inhibition in the manganese-depleted membranes as represented by the descending tendency of the corresponding curves after reaching their maxima. The different electron donation capability of these compounds, especially at low concentration, can be explained by their different redox potential and/or steric reasons (e.g. accessibility to the site of electron donation). Surprisingly, at low concentration $(<50 \mu \mathrm{M})$ the trinuclear manganese complex (triangles) had higher electron donation capacity than $\mathrm{MnCl}_{2}$.

Electron donation experiments were carried out by using synthetic bi- and tetranuclear manganese complexes, too. Fig. $2 \mathrm{~A}$ shows the effects of five different binuclear complexes. At low concentrations $(5-50 \mu \mathrm{M})$ all of the complexes had normal electron donation capability, whereas at higher concentration $(>100-200 \mu \mathrm{M})$, due to the mentioned unidentified inhibition, only the donation of the $\mathrm{M}-2\left(\mathrm{~L}_{4}\right)$ complex exceeded the value belonging to manganese-depleted samples. This is surprising, since $\mathrm{M}-2\left(\mathrm{~L}_{4}\right)$ binuclear complex, in addition to 2-hydroxy naphthoquinone, also contains 1,10-phenanthroline with a molar ratio of $2: 2\left(\mathrm{~L}_{8}\right.$ to $\mathrm{Mn}$ ) which ratio is close to the $\mathrm{L}_{8}$ to $\mathrm{Mn}$ ratio of $M-3\left(L_{8}\right)$ (4:3). Nevertheless, their electron donation capability significantly differs from each other. M-2 $\left(\mathrm{L}_{4}\right)$ donates electron toward P680 similarly as $\mathrm{MnCl}_{2}$ in the whole examined concentration range, while $\mathrm{M}-3\left(\mathrm{~L}_{8}\right)$ behaves differently at low and at high concentrations: electron donation capability of the trinuclear manganese complex is higher at low concentrations and lower at high concentrations than belonging to $\mathrm{MnCl}_{2}$. This different behaviour cannot be explained by the different valence state of the $\mathrm{Mn}$ in $\mathrm{M}-3\left(\mathrm{~L}_{8}\right)$ and $\mathrm{M}$ $2\left(\mathrm{~L}_{4}\right)$ [Mn(III) and $\mathrm{Mn}(\mathrm{II})$, respectively] (see the decrease the electron donation capability of all but one $\left[\mathrm{M}-2\left(\mathrm{~L}_{4}\right)\right]$ mono-, bi- and trinuclear complexes), thus the efficiency of the manganese complexes in electron donation highly depends on not only the nature of the ligands but on the structure of the complex, too. The sufficient electron donation capability of $\mathrm{M}-\left(\mathrm{L}_{4}\right)$ complex supports the data that binuclear $\mathrm{Mn}(\mathrm{III})$ complexes containing 2-hydroxy-1,4 naphthoquinone monoxime, which differs from the $\mathrm{L}_{4}$ (= 2-hydroxy-1,4 naphthoqui- 


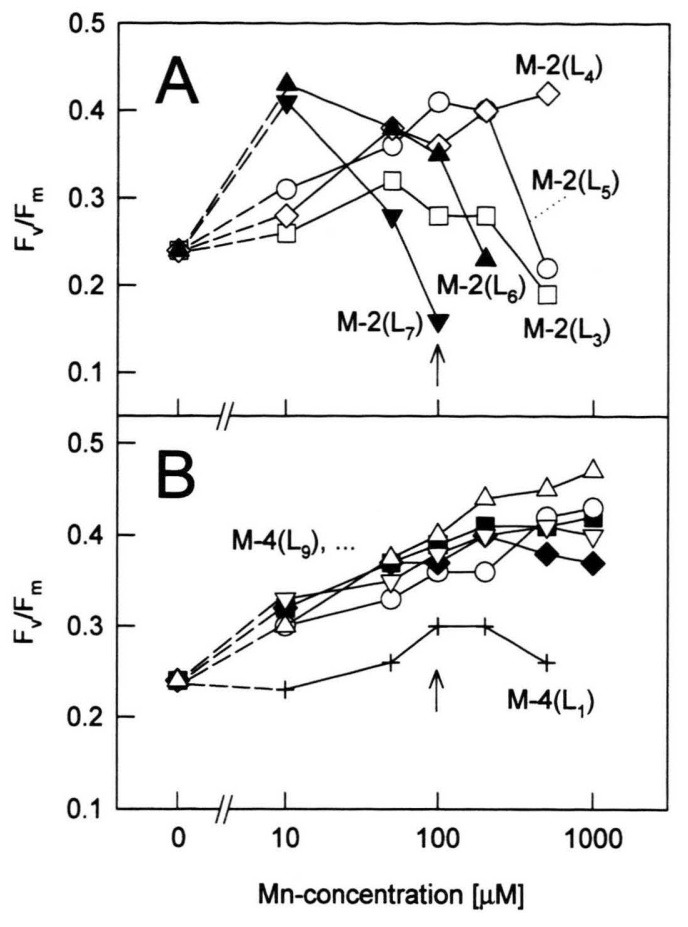

Fig. 2. Effect of binuclear (A) and tetranuclear (B) manganese complexes on the normalized maximal variable fluorescence of manganese-depleted thylakoid membranes. Squares, diamonds, circles, filled standing and filled reversed triangles on panel $A$ represent the $F_{v} / F_{m}$ values belonging to $\mathrm{M}-2\left(\mathrm{~L}_{3}\right), \mathrm{M}-2\left(\mathrm{~L}_{4}\right), \mathrm{M}-2\left(\mathrm{~L}_{5}\right), \mathrm{M}-2\left(\mathrm{~L}_{6}\right)$ and $\mathrm{M}-2\left(\mathrm{~L}_{7}\right)$, respectively. Crosses, filled squares, circles, filled diamonds, standing and reversed triangles on panel $B$ show the values after electron donation with $\mathrm{M}-1\left(\mathrm{~L}_{1}\right)$, $\mathrm{M}-4\left(\mathrm{~L}_{9}\right), \mathrm{M}-4\left(\mathrm{~L}_{10}\right), \mathrm{M}-4\left(\mathrm{~L}_{11}\right), \mathrm{M}-4\left(\mathrm{~L}_{12}\right)$ and $\mathrm{M}-4\left(\mathrm{~L}_{13}\right)$, respectively. The arrows indicate the applied concentration in the case of photoactivation.

none) ligands only by one functional group, also have high efficiency in electron donation (Allakhverdiev et al., 1994a).

Similarly to $\mathrm{M}-3\left(\mathrm{~L}_{8}\right)$ trinuclear complex, electron donation capacity of two binuclear complexes, $\mathrm{M}-2\left(\mathrm{~L}_{6}\right)$ and $\mathrm{M}-2\left(\mathrm{~L}_{7}\right)$ was higher than that of $\mathrm{MnCl}_{2}$ at low concentration $(<20-50 \mu \mathrm{M})$. In these complexes having a very similar structure manganese ions exist in mixed valence state [Mn(II) and Mn(III)]. Thus it is possible that the reason of the observed high efficiency in electron donation at low concentrations in the case of $M-3\left(L_{8}\right), M-2\left(L_{6}\right)$ and $M-2\left(L_{7}\right)$ is the higher valence state of the manganese ions in these complexes.
In addition to 1,10-phenanthroline there is another ligand existing not only in binuclear manganese complexes: both $\mathrm{M}-1\left(\mathrm{~L}_{2}\right)$ and $\mathrm{M}-2\left(\mathrm{~L}_{3}\right)$ complexes contains 3,5-di-tert-butyl-1,2-benzoquinone monoxime $\left(=\mathrm{L}_{2}=\mathrm{L}_{3}\right)$. By comparing the certain curves in Fig. 1A and in Fig. 2A it can be observed that the electron donation capability of $\mathrm{M}-2\left(\mathrm{~L}_{3}\right)$ binuclear complex (which has lower electron donation capability than that of other binuclear complexes) is significantly better than belonging to $\mathrm{M}$ $1\left(\mathrm{~L}_{2}\right)$ mononuclear complexes (which is approximately zero). This observation also indicates the relationship between the structure and efficiency in electron donation of the complexes.

Although M-2 $\left(\mathrm{L}_{6}\right)$ and $\mathrm{M}-2\left(\mathrm{~L}_{7}\right)$ complexes, due to the close similarity between $\mathrm{L}_{6}$ and $\mathrm{L}_{7}$ ligands (= acetylphthiocolmonoxime and propionylphthiocolmonoxime, respectively, they differ from each other only by a methylene group), have analog chemical structure, their electron donation capabilities are different: $F_{v} / F_{m}$ values belonging to $M$ $2\left(\mathrm{~L}_{7}\right)$ complex having larger ligand and consequently larger total size decreases faster after reaching the maximum appearing around $10 \mu \mathrm{m}$. Thus not only the structure alone, but also the size of the complexes has effect on the efficiency in electron donation.

Among the probed synthetic manganese complexes the largest group is the tetranuclear compounds. They can be divided into two parts: the salicylaldoxime $\left(=\mathrm{L}_{1}\right)$ containing $\mathrm{M}-4\left(\mathrm{~L}_{1}\right)$ complex has tetragonal, while the remaining five complexes have an analog linear, dimer+dimer structure (Theil et al., 1997). This analogy is caused by the similarity of the $\mathrm{L}_{9}-\mathrm{L}_{13}$ complexes: all of them are cathecolimines substituted by different aromatic groups. Due to this reason the concentration dependence of the $F_{v} / F_{m}$ ratios after addition of these compounds to manganese-depleted thylakoid membranes do not show a high-grade heterogeneity as in the case of binuclear complexes. Their concentration dependence also can be divided into two groups: the $\mathrm{M}-4\left(\mathrm{~L}_{1}\right)$ complex proved to be weak, the cathecolimine containing complexes proved to be strong electron donors (Fig. 2B). In equimolar concentrations all of the manganese-cathecolimine complexes had similar $\mathrm{F}_{\mathrm{v}} / \mathrm{F}_{\mathrm{m}}$ values and the tendency of change was also identical. Within this homolog group, at high concentrations $(>200 \mu \mathrm{M})$ the $\mathrm{M}-4\left(\mathrm{~L}_{12}\right)$ complex 
proved to be the most potent electron donor: the corresponding $\mathrm{F}_{\mathrm{v}} / \mathrm{F}_{\mathrm{m}}$ ratio was higher than in the presence of $\mathrm{MnCl}_{2}$. Two explanations can be provided for this phenomenon. According to the first one, the chemical structure of $\mathrm{L}_{12}$ is significantly different from that of the other $\mathrm{L}_{\mathrm{x}}(\mathrm{x}=9,10,11,13)$ ligands: instead of pyrimidyl $\left(\mathrm{L}_{9}, \mathrm{~L}_{10}, \mathrm{~L}_{13}\right)$ or substituted phenyl group $\left(\mathrm{L}_{11}\right)$ it contains a benzimidazolyl group which may modify the redox potential of the $\mathrm{M}-4\left(\mathrm{~L}_{12}\right)$ complex. The second, more possible explanation is that the $\mathrm{L}_{12}$ ligand itself can also donate electrons to PS II, which was experimentally proven (data not shown). This fact should also be considered in the interpretation of the observations reported by Allakhverdiev et al. (1994a). According to their results higher $F_{v} / F_{m}$ ratio can be reached by addition of the same amount of binuclear manganese complexes as $\mathrm{MnCl}_{2}$ (naturally, normalised to the manganese content). It cannot be excluded that in their experiments the applied complexing agent, 2-hydroxy-1,4-naphthoquinone monoxime also acted as electron donor. Supporting our assumption the 4-hydroxy-2-oxo tautomeric form of the oxime greatly resembles the structure of 1,4-quinols, which proved to be efficient donors towards P680, the primary electron donor of PS II, in manganese-depleted PS II particles (data not shown).

The $M-4\left(L_{1}\right)$ complex differs from the other tetranuclear complexes not only by structurally but by the valence state of its manganese ions $[\mathrm{Mn}(\mathrm{III})]$, too. Its electron donation capability does not exceed the efficiency of $\mathrm{MnCl}_{2}$ nor at low neither at high concentrations. Thus it can be excluded that the high electron donation capacity of $\mathrm{M}-3\left(\mathrm{~L}_{8}\right)$, trinuclear and $\mathrm{M}-2\left(\mathrm{~L}_{6}\right)$ and $\mathrm{M}-2\left(\mathrm{~L}_{7}\right)$ complexes can be explained only by the valence state of manganese ions. However, this characteristics is observed only in the case of $\mathrm{Mn}$ (III)-containing complexes, thus it is possible, the higher valence state of the $\mathrm{Mn}$-ions is indispensable for this phenomenon. According the different behaviour of $\mathrm{M}-4\left(\mathrm{~L}_{1}\right)$, existence of other unidentified factor(s) is (are) also necessary.

The synthesized mono-, bi-, tri- and tetranuclear manganese probes were also tested in photoactivation experiments. The photosynthetic activity of the reactivated samples was measured by fluorescence induction technique as well as by continuous and flash oxygen polarography and thermolumi- nescence. It is important to emphasise that in these cases the restoration of the photosynthetic parameters was achieved by the incorporation of the manganese ions to PS II, not by single (exogenous) electron donation of them. The applied concentration was $100 \mu \mathrm{M}$ of mononuclear or equivalent amounts of bi-, tri- or tetranuclear complexes (represented as arrows in Fig. 1B, 2A and 2B). Fig. 3A illustrates the incorporation of $\mathrm{Mn}^{2+}$ followed by fluorescence induction. The photosynthetic activity was estimated by the differences of $F_{v}$ values of reactivated and manganese-depleted samples (marked with $F_{v}$ '). Normalized values are
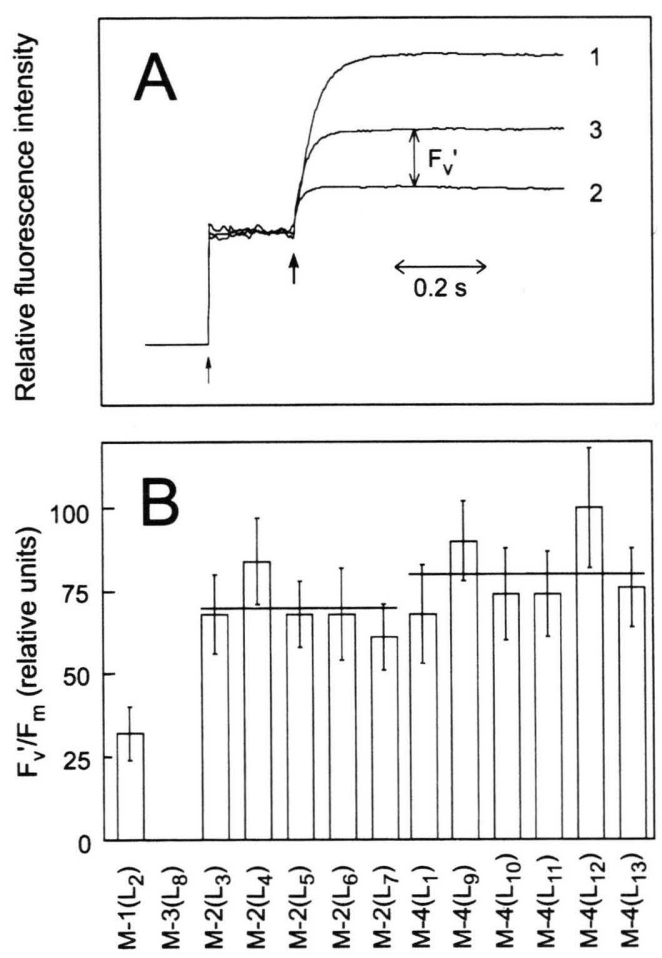

Fig. 3. Manganese depletion and subsequent photoactivation of the WOC using synthetic manganese complexes as monitored by fluorescence induction. (A) Fluorescence induction curves of (1) control thylakoids; (2) manganese-depleted thylakoids and (3) thylakoid membranes photoactivated by $\mathrm{MnCl}_{2}$. Switching on the measuring- $\left(0.1 \mathrm{~W} / \mathrm{m}^{2}\right)$ and actinic beam $\left(10 \mathrm{~W} / \mathrm{m}^{2}\right)$ are indicated by thin and thick arrows, respectively. (B) Normalized $\mathrm{F}_{\mathrm{v}} / \mathrm{F}_{\mathrm{m}}$ values of thylakoid membranes photoactivated by $100 \mu \mathrm{M} \mathrm{MnCl}_{2}$ or equivalent amounts of different manganese complexes $\left(\mathrm{MnCl}_{2}=100 \%\right)$. The horizontal lines over the columns represent the averages of two different groups (bi- and tetranuclear complexes) of the synthetic manganese compounds. Error bars are indicated. 
shown in Fig. 3B (The $\mathrm{F}_{\mathrm{v}} / \mathrm{F}_{\mathrm{m}}$ ratio is 0.24 and 0.48 in manganese-depleted and $\mathrm{MnCl}_{2}$-reactivated samples, respectively). The reason of the partial restoration can be explained by partial photoinhibition during the photoactivation procedure (Rova et al., 1996). [The enhanced sensitivity of manganese-depleted PS II particles against donor side photoinhibition which takes place even at low light regime was reviewed by Aro and her coworkers (1992).] As can be seen the efficiency of the synthetic complexes in the restoration of the $F_{v}$ ' values follows the $\mathrm{M}-3\left(\mathrm{~L}_{8}\right)<\mathrm{M}-1\left(\mathrm{~L}_{2}\right)<$ binuclear complexes $<$ tetranuclear complexes order. With one exception [M-3 $\left(\mathrm{L}_{8}\right)$ cannot restore the photosynthetic activity] the orders of the efficiency within the three groups (mono-/tri-, bi- and tetranuclear complexes) in the photoactivation is the same as in the electron donation experiments at $100 \mu \mathrm{M}$ Mn-concentration (Fig. 1B, 2A and 2B, respectively). This cannot be considered as an obvious fact because the site of electron donation is not necessarily identical with the in vivo binding site of manganese. Especially, if we take into account that during photoactivation the protein structure of the lumenal side of PS II is rearranged (Tamura and Cheniae, 1987; Ananyev et al., 2001). However, in Ghirardi's works (Ghirardi et al., 1998; and references therein) it was suggested that the action sites of 1,5-diphenylcarbazide (DPC) photooxidation was identical with the physiological Mn-binding sites of WOC.

There are similarities between the results of electron donation and photoactivation in respect of the efficiency of $\mathrm{Mn}$ (II)- and $\mathrm{Mn}$ (III)-containing complexes in these experiments, too: the efficiencies of $\mathrm{Mn}$ (III)-containing complexes is lower than $\mathrm{Mn}$ (II)-containing ones. The possible reason of this the different chemical nature of these complexes which render a more difficult incorporation of their manganese ions into WOC. The partial or total incorporation of these complexes also cannot be excluded. In this case the modified WOC may donate electrons toward P680 with lower efficiency than the normal one. A subsequent similarity between the results of electron donation and photoactivation experiments the significant difference between $\mathrm{M}-1\left(\mathrm{~L}_{2}\right)$ mononuclear and $\mathrm{M}$ $2\left(\mathrm{~L}_{3}\right)$ binuclear complexes which contain same kind of ligands. This indicates that not only the exogenous electron donation depends on the structure of the complex but also the incorporation and/or the function of the reactivated water splitting complex.

After photoactivation the photosynthetic activity was also investigated by oxygen polarography. The relatively high yield of oxygen evolution of thylakoid membranes (Fig. 4A, curve 1) is almost completely eliminated by extraction of the four manganese ions of WOC (Fig. 4A, curve 2). Execution of photoactivation experiment by different manganese-containing compounds resulted in a partial restoration of the photosynthetic activity
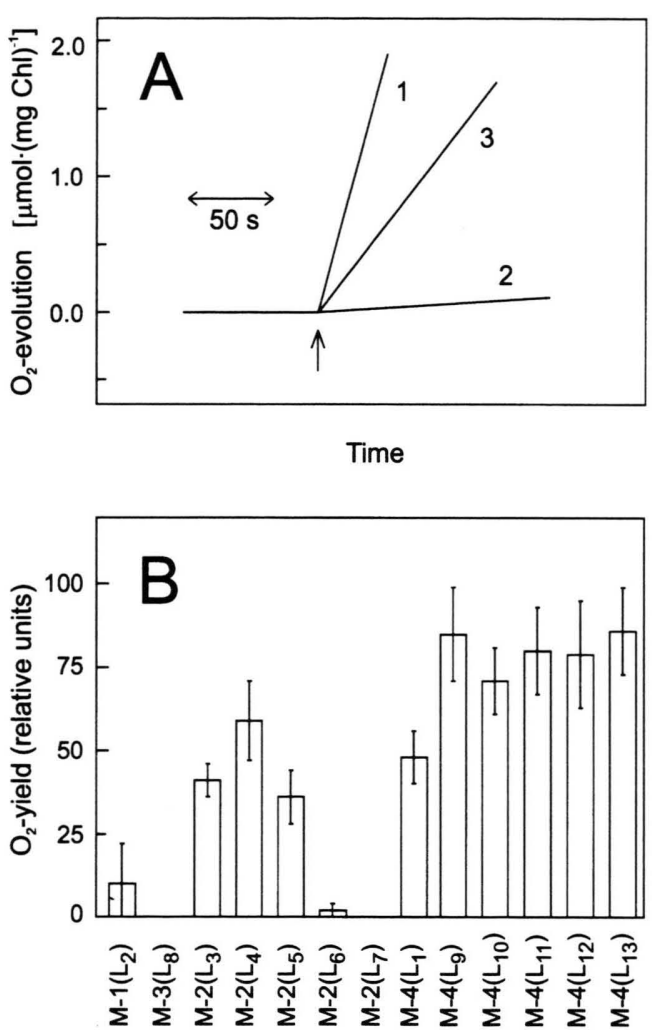

Fig. 4. Manganese depletion and subsequent photoactivation of the WOC using synthetic manganese complexes as monitored by Clark-type oxygen electrode. (A) Rate of oxygen evolution of (1) control thylakoid; (2) manganese-depleted thylakoid and (3) thylakoid membranes photoactivated by $100 \mu \mathrm{M} \mathrm{MnCl}_{2}$. The arrow indicates the onset of the saturating white light. ([Chl] = $50 \mu \mathrm{m} / 1.5 \mathrm{ml}$ ). $500 \mu \mathrm{M}$ phenyl-p-benzoquinone was used as electron acceptor. The $\mathrm{O}_{2}$ yield of the control samples (the slope of curve 1) was $170 \mu \mathrm{mol} \cdot(\mathrm{mg} \mathrm{Chl})^{1} \cdot \mathrm{h}^{1}$. (B) Normalized $\mathrm{O}_{2}$ yields of thylakoid membranes photoactivated by $100 \mu \mathrm{M} \mathrm{MnCl}_{2}$ or equivalent amounts of different manganese complexes $\left(\mathrm{MnCl}_{2}=100 \%=\right.$ $120 \mu \mathrm{mol} \cdot\left(\mathrm{mg} \mathrm{Chl}^{1} \cdot \mathrm{h}^{1}\right)$. Error bars are indicated. 
(Fig 4A, curve 3). Using $100 \mu \mathrm{M} \mathrm{MnCl}_{2}$ up to $70 \%$ restoration could be achieved which can be considered satisfactory (Miyao and Inoue, 1991b).

Fig. 4B shows the relative restoration of the steady state oxygen evolution by the tested complexes during photoactivation (restoration by $\mathrm{MnCl}_{2}$ is considered as $100 \%$ ). In all cases the relative activity is slightly smaller than that obtained by fluorescence induction since oxygen evolution is a more complex phenomenon and rather in vivo property than fluorescence. No detectable oxygen evolution could be measured after restoration by M-3 $\left(\mathrm{L}_{8}\right)$ and M-2 $\left(\mathrm{L}_{7}\right)$ complexes and only a small one in the case of $\mathrm{M}-2\left(\mathrm{~L}_{6}\right)$ reconstituted samples. We have tried to carry out photoactivation by these binuclear complexes at lower concentration, too, when their electron donation is more pronounced (see Fig. 1B and 2A), but the attempts were unsuccessful. The order of the restoration is almost the same as mentioned in fluorescence induction: tetranuclear manganese complexes were better than mono-, bi- and trinuclear ones. Within bi- and tetramers, complexes having only $\mathrm{Mn}$ (II) ions proved to be better than those (also) having $\mathrm{Mn}(\mathrm{III})$. The $\mathrm{M}-4\left(\mathrm{~L}_{1}\right)$ complex having a tetragonal Mn setting had a lower capability in restoration the oxygen evolving properties of manganese depleted thylakoid membranes.

For getting more detailed information about the oxygen evolution of the samples polarographic signals were also detected by a Joliot-type oxygen electrode before and after photoactivation. The pattern of the control sample followed the wellknown oscillation with a period of four with the first maximum at the 3rd flash (Fig. 5A, curve 1). After manganese depletion the signal was almost totally abolished (Fig. 5A, curve 2). The photoactivated samples exhibited two very different flash oxygen yield patterns (Fig. 5A, curves 3 and 4).

All of the probed synthetic tetra-, mono- and one of the binuclear complexes (Fig. 5A, curve 3) had a partial restoration with the same period four oscillation pattern. The absolute values were relatively low in comparison with the control sample (maximum 20\%) due to the limited size of the plastoquinone pool. The relative values of oxygen yields obtained with this type of complexes are presented in Fig. $5 \mathrm{~B}\left(\mathrm{MnCl}_{2}=100 \%\right)$. With one exception $\left[\mathrm{M}-4\left(\mathrm{~L}_{11}\right)\right]$ the relative flash oxygen yields were proportional with or larger than the
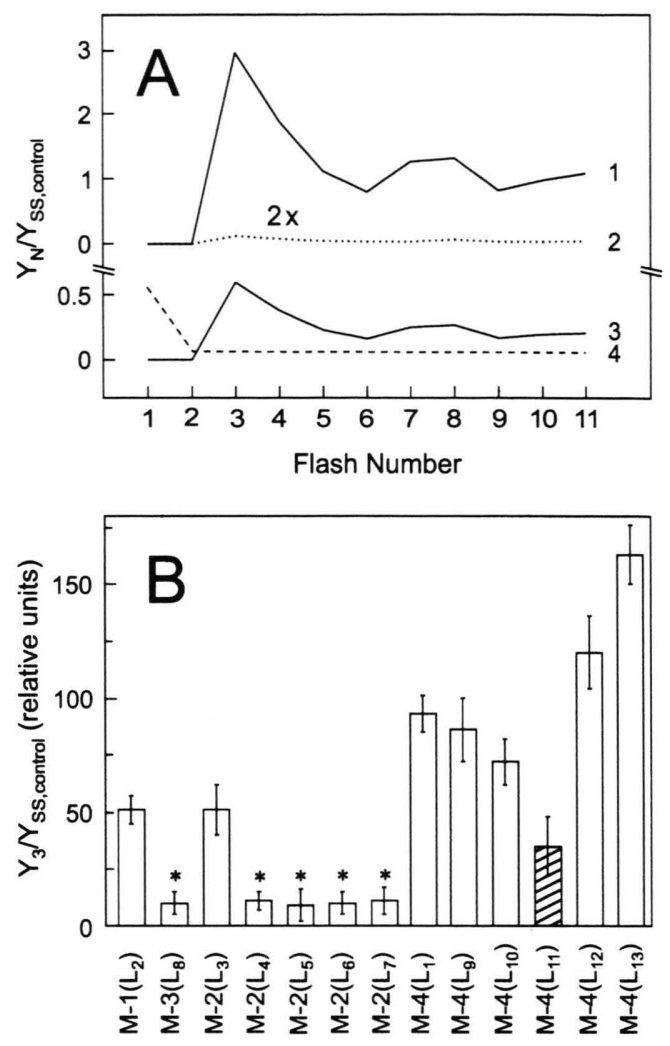

Fig. 5. Manganese depletion and subsequent photoactivation of the WOC using synthetic manganese complexes as monitored by Joliot-type oxygen electrode. (A) Patterns of oxygen evolution induced by one-turnoverflashes of (1) control thylakoid; (2) manganese-depleted thylakoid and thylakoid membranes photoactivated by (3) $\mathrm{MnCl}_{2}$ and (4) M-3( $\left.\mathrm{L}_{8}\right)$. (B) Normalized $\mathrm{O}_{2}$ yields of thylakoid membranes after the 3 rd flashes photoactivated by $100 \mu \mathrm{M} \mathrm{MnCl}_{2}$ or equivalent amounts of different manganese complexes $\left(\mathrm{MnCl}_{2}=100 \%\right)$. The strange flash oxygen patterns (curve 3 in panel A) are signed by stars. Since oxygen evolution of the M-4 $\left(\mathrm{L}_{11}\right)$ reconstituted samples is accompanied with respiration the value of the striped column should be considered carefully. Error bars are indicated.

continuous yields (Fig. 4B). There was close correlation with the $\mathrm{M}-1\left(\mathrm{~L}_{2}\right)<\mathrm{M}-2\left(\mathrm{~L}_{3}\right)<$ tetranuclear complexes order obtained in the fluorescence induction and steady state oxygen experiments. In the case of $\mathrm{M}-4\left(\mathrm{~L}_{11}\right)$ complex, respiration was observable which distorted the results, which may be explained by the different, O-O-N-O donor atom set of the $\mathrm{L}_{11}$ ligand, contrary to O-O-N-N set of the other cathecolimine ligands. Thus the oxygen evolution belonging to $\mathrm{M}-4\left(\mathrm{~L}_{11}\right)$ complex is probably higher than that can be read from Fig. 4. It is re- 
markable that in two cases [M- $4\left(\mathrm{~L}_{12}\right)$ and $\mathrm{M}-4\left(\mathrm{~L}_{13}\right)$ ] the observed activity was higher than that obtained with $\mathrm{MnCl}_{2}$. This result provided indirect evidence that not only the dissociated manganese ions as in the case of $\mathrm{MnCl}_{2}$ but the whole $\mathrm{M}-4\left(\mathrm{~L}_{12}\right)$ and $\mathrm{M}$ $4\left(\mathrm{~L}_{13}\right)$ complex can (partially or totally) be incorporated into WOC. Similarly, photoactivation of spinach PS II particles (depleted of extrinsic proteins) by tetranuclear complex resulted in higher (continuous) oxygen yield than by using $\mathrm{MnCl}_{2}$ (data not shown). These complexes can probably produce better restoration energetically or kinetically than simple $\mathrm{Mn}^{2+}$ but in the intact thylakoid membranes the water-soluble extrinsic proteins hinder their binding sterically. In accordance with this it has been published that the Synechocystis $\Delta \mathrm{psbO}$ mutant lacking $33 \mathrm{kDa}$ manganese stabilizing protein presented higher $\mathrm{Mn}^{2+}$ accessibility than the wide type (Burnap et al., 1995).

The remaining four bi- and the investigated trinuclear complex produced a strange oxygen yield pattern without any oscillation (Fig. 5A, curve 4). These patterns show large oxygen release after the first flash. After the second flash the oxygen yield was very low and almost completely disappeared after subsequent flashes. This indicates that these reconstituted centers are trapped in stable $S_{3}$ state after dark incubation and one ore more subsequent S-state transition(s) $\left(\mathrm{S}_{0} \rightarrow \mathrm{S}_{1}, \mathrm{~S}_{1} \rightarrow \mathrm{S}_{2}, \mathrm{~S}_{2} \rightarrow \mathrm{S}_{3}\right)$ is (are) inhibited. It has been published that oxygen produced in cyanobacteria after the first (and partially the second) flash. This oxygen release is also attributed to metastable $\mathrm{S}_{3}$ redox state (Bader et al., 1983; Bader, 1994). Oxygen evolution from special PS II preparations after the first flash has also been reported (Lavorel and Seibert, 1982). It is an interesting parallelism that three of the probed $\mathrm{Mn}$ (III) containing complexes produced such strange oxygen pattern. Thus, complexes in which the manganese ions exist in higher oxidation state can build up water splitting complex having larger stability in higher S-states. Thus, we concluded that these bi- and trinuclear complexes can be incorporated into WOC, but it cannot perform normal photosynthesis: the reconstituted WOC is modified or perturbed.

It is a remarkable that three of the complexes exhibiting unusual oxygen yield pattern $\left[\mathrm{M}-3\left(\mathrm{~L}_{8}\right)\right.$, $\mathrm{M}-2\left(\mathrm{~L}_{6}\right)$ and $\left.\mathrm{M}-2\left(\mathrm{~L}_{7}\right)\right]$ at low concentration have higher electron donation capacity than $\mathrm{MnCl}_{2}$
(Fig. 1B and 2A), but cannot exhibit steady state oxygen evolution (Fig. 4B). All of them contains $\mathrm{Mn}(\mathrm{III})$ ions. This may suggest that the valence state of Mn-ions, evidently, highly influence the redox properties of the complexes. However, role of the chemical nature of the ligands and the structure of the complexes are not to be doubt [see the strange flash oxidation patterns of the Mn(II)containing $\mathrm{M}-2\left(\mathrm{~L}_{4}\right)$ and $\mathrm{M}-2\left(\mathrm{~L}_{5}\right)$ complexes or the normal pattern of $\mathrm{Mn}(\mathrm{III})$ containing $\mathrm{M}-4\left(\mathrm{~L}_{1}\right)$ complex].

For the investigation of the redox potential changes of WOC during the photoactivation procedure TL glow curves also were recorded. Thermoluminescence and oxygen polarimetry give more reliable data about manganese binding than fluorescence measurements because the main TL bands and the $\mathrm{O}_{2}$ signal can be obtained only from incorporated manganese ions. The position of a TL peak is determined by the redox distance between the interacting oxidized donor and reduced acceptor (reviewed by Vass and Inoue, 1992). Any change in the redox potential of the positively charged donor (S-state) can shift the peak position of the corresponding TL band. We investigated the effect of manganese complexes on the amplitude and peak position of the Q TL band $\left(\mathrm{S}_{2} \mathrm{Q}_{\mathrm{A}}{ }^{-}\right.$ charge recombination) which appears in the glow curve at about $0^{\circ} \mathrm{C}$ in the presence of DCMU (an inhibitor acting between $\mathrm{Q}_{\mathrm{A}}$ and $\mathrm{Q}_{\mathrm{B}}$ ). Fig. 6A, curve 1 and 2 represent the TL glow curve of thylakoid membranes before and after manganese depletion, respectively. Fig 6A, curve 3 represents the TL spectra of a reactivated sample. After manganese depletion (Fig. 6A, curve 2) the Q-band was considerably decreased and a new TL-band appeared at around $-25^{\circ} \mathrm{C}\left(\mathrm{A}_{\mathrm{T}}\right.$-band $)$ which can be associated with $\mathrm{His}^{+} \mathrm{Q}_{\mathrm{A}}{ }^{-}$recombination (Ono and Inoue, 1991). Reactivation of manganese-depleted thylakoid membranes by equimolar amount of $\mathrm{MnCl}_{2}$ resulted in a partial reappearance of the Q-band and a total disappearance of the $\mathrm{A}_{\mathrm{T}}$-band (Fig 6A, curve 3). Similar phenomenon has been described by Tamura et al. (1989). The peak position of the Q-band has not changed during the reactivation processes indicating that binding of the complexes resulted in the formation of the ordinary $S_{2}$ state.

Fig. $6 \mathrm{~B}$ shows the normalized $\left(\mathrm{MnCl}_{2}=100 \%\right)$ average values of the Q-band after reactivation by 

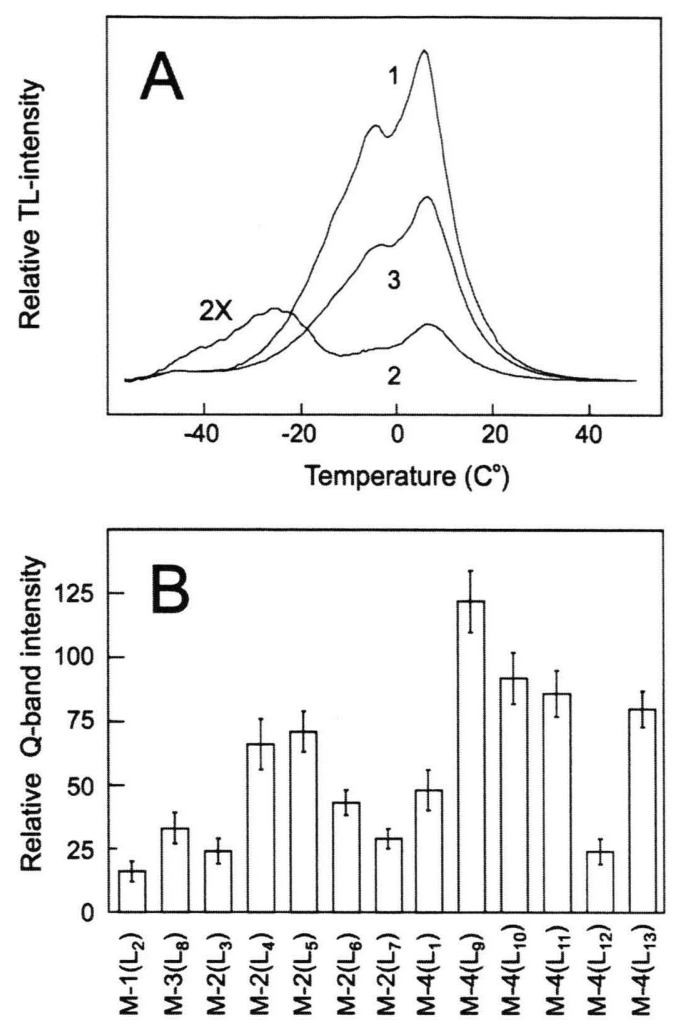

Fig. 6. Manganese depletion and subsequent photoactivation of the WOC using synthetic manganese complexes as monitored by thermoluminescence. The thermoluminescence glow curves were measured in the presence of $10 \mu \mathrm{M}$ DCMU. (A) TL glow curves of (1) control thylakoids; (2) manganese-depleted thylakoids and thylakoid membranes photoactivated by (3) $100 \mu \mathrm{m}$ $\mathrm{MnCl}_{2}$. (B) Normalized Q-band intensity of thylakoid membranes photoactivated by $100 \mu \mathrm{M} \mathrm{MnCl}_{2}$ or equivalent amounts of different manganese complexes $\left(\mathrm{MnCl}_{2}=100 \%\right)$. Error bars are indicated.

different manganese complexes. The maximum of the corresponding Q-band intensities $\left[\mathrm{M}-4\left(\mathrm{~L}_{9}\right)\right]$ is about $70 \%$ of the control thylakoid amplitude, the same as the yield observed in oxygen polarographic measurements. This means that this complex were more effective in the reconstitution of the $\mathrm{Q}$ band than $\mathrm{MnCl}_{2}$. The efficiency of photoactivation showed the same sequence (tetra- > bi- > mononuclear, trinuclear complexes) as obtained in fluorescence induction (Fig. 3) and oxygen yield (Fig. 4) measurements. Surprisingly, the Q-band could be reactivated by the binuclear and trinuclear complexes which could not restore the steady state oxygen evolution (Fig. 4B) and the period-4 flash oxygen yield pattern (Fig. 5). This indicates, that the $S_{2} \rightarrow S_{3}$ transition was inhibited in a higher extent than the $S_{1} \rightarrow S_{2}$ transition. This can be reconciled with the data that the same complexes proved to be very efficient donors to WOC in fluorescence induction experiments (Fig. 1B and $2 \mathrm{~A}$ ).

By comparison of the results of the fluorescence induction, polarographic and TL measurements, it can be concluded that tetranuclear complexes were more effective than mono-, bi- and trinuclear complexes in all of these types of experiments. It may indirectly indicate that all four manganese ions are required for water splitting in contradiction with the suggestions of Klimov et al. (1982), Saygin and Witt (1987) as well as Allakhverdiev et al. (1994a). High efficiency of some binuclear complexes in these experiments can be explained by the concerted action of two binuclear complexes. The very low efficiency of the $M-3\left(L_{8}\right)$ trinuclear complex supports this idea. It is important that the more efficient five tetranuclear complexes have a dimer+dimer structure resembling the natural structure of WOC.

The efficiency of the complexes in photoactivation experiments can also be compared by the types of the ligands. In most of the probed 13 complexes the manganese ions were ligated by $4-6$ oxygen and $0-2$ nitrogen atoms. Two exceptions are the $\mathrm{M}-1\left(\mathrm{~L}_{2}\right)$ mononuclear complex where $\mathrm{Cl}^{-}$ ions also plays role as donor atoms and the $\mathrm{M}$ $3\left(\mathrm{~L}_{8}\right)$ trinuclear complex in which manganese ions have four nitrogen and two oxygen donor atoms. Both of these complexes had low efficiency at the restoration of photosynthetic functions. Thus, the donor atom set of the manganese ions may also play role in the efficiency of photoactivation. Although the amino acid residues and donor atoms participating in the binding of the manganese ions of WOC are to be answered, based on the sequence analysis of $\mathrm{D} 1$ and $\mathrm{D} 2$ reaction center proteins and on characterization of numerous pointmutants, there are several indications for them (for reviews, see Debus, 1992, 2001; Diner, 2001). Most of the donor atoms to manganese in WOC is probably oxygen, which are resistant against $\mathrm{Mn}(\mathrm{IV})$ existing in higher S-states. However there are indications that histidine residues also participate in the ligation of manganese ions. Thus, the $\mathrm{O}-\mathrm{N}$ donor atom distribution of WOC and the 
probed synthetic complexes are close to each other.

Thirteen synthetic manganese complexes were probed in electron donation and photoactivation experiments. They can be divided into groups by several ways: by number and valence state of central manganese ions, by donor atom distribution and structure of the complexes. By comparison of the number of the variable parameters and of the probed complexes it is evident that our conclusions were drawn by a few samples. Thus, in several cases it was impossible to decide which factor was the dominant (if several factors were changed at the same time or in the cases of types which were represented by only one or two sam-

Aggarwal R. C., Singh N. K. and Singh R. P. (1984), Magnetic and spectroscopic studies on salicylaldoxime and o-hydroxynaphthaldoxime complexes of some divalent $3 d$ metal ions. Synth. React. Inorg. Met.-Org. Chem. 14, 637-650.

Allakhverdiev S. I., Karacan M. S., Somer G., Karacan N., Khan E. M., Rane M. Y. Padhye S., Klimov V. V. and Renger G. (1994a), Reconstitution of the wateroxidizing complex in manganese-depleted photosystem II complexes by using synthetic binuclear manganese complexes. Biochemistry 33, 12210-12214.

Allakhverdiev S. I., Karacan M. S., Somer G., Karacan N., Khan E. M., Rane M. Y., Padhye S., Klimov V. V. and Renger G. (1994b), Binunclear manganese(III) complexes as electron donors in D1/D2/cytochrome b559 preparations isolated from spinach photosystem II membrane fragments. Z. Naturforsch. 49c, 587-592.

Allakhverdiev S. I., Ozdemir U., Harnois J., Karacan N., Hotchandani S., Klimov V. V., Murata N. and Carpentier R. (1999), Reconstitution of the water-oxidizing complex in manganese-depleted photosystem II preparations using mononuclear manganese complexes. Photochem. Photobiol. 70, 57-63.

Ananyev G. M., Zaltsman L., Vasko G. C. and Dismukes G. C. (2001), The inorganic biochemistry of photosynthetic oxygen evolution/water oxidation. Biochim. Biophys. Acta 1503, 52-68.

Aro E.-M., Virgin I. and Andersson B. (1993), Photoinhibition of photosystem II. Inactivation, protein damage and turnover. Biochim. Biophys. Acta 1143, $113-134$

Bader K. P. (1994), Physiological and evolutionary aspects of the $\mathrm{O}_{2} / \mathrm{H}_{2} \mathrm{O}_{2}$-cycle in cyanobacteria. Biochim. Biophys. Acta 1188, 213-219.

Bader K. P., Thibault P. and Schmid G. H. (1983), A study on oxygen evolution and on the S-state distribution in thylakoid preparations of the filamentous bluegreen-alga Oscillatoria chalybea. Z. Naturforsch. 38c, $778-792$. ples). Let it be said in the excuse of the authors of this article that composition of the complexes are cannot be chosen freely and cannot be altered continuously. Probing of other synthetic manganese complexes in electron donation and photoactivation experiment will serve additional valuable information about photoactivation and structure of WOC.

\section{Acknowledgements}

This work was supported by the Hungarian National Science Foundation (OTKA: T 025684 and F 029144). The authors thank Drs. Stenbjörn Styring and Fikret Mamedov for critical reading of the manuscript.

Britt R. D. (1996), Oxygen evolution. In: Oxygenic Photosynthesis: The Light Reactions (Ort D. R., and Yocum C. F, eds.). Kluwer Academic Publ., Dordrecht, pp. $137-164$.

Burnap R. L., Quian M. and Pierce C. (1996), The manganese-stabilizing protein of photosystem II modifies the in vivo deactivation and photoactivation kinetics of the $\mathrm{H}_{2} \mathrm{O}$ oxidation complex in Synechocystis sp. PCC6803. Biochemistry 35, 874-882.

Chen C., Kazimir J. and Cheniae G. M. (1995), Calcium modulates the photoassembly of photosystem II $(\mathrm{Mn})_{4}$-clusters by preventing ligation of nonfunctional high-valency states of manganese. Biochemistry 34, $13511-13526$.

Debus R. J. (1992), The manganese and calcium ions of photosynthetic oxygen evolution. Biochim. Biophys. Acta 1102, 269-352.

Debus R. J. (2001), Amino acid residues that modulate the properties of $\mathrm{Y}_{\mathrm{Z}}$ and the manganese cluster in the water oxidizing complex of photosystem II. Biochim. Biophys. Acta 1503, 164-186.

Demeter S., Rózsa Zs., Vass I. and Sallai A. (1985), Thermoluminescence study of charge recombination in photosystem II at low temperatures. I. Characterization of the $Z_{v}$ and $A$ thermoluminescence bands. Biochim. Biophys. Acta 809, 369-378.

Diner B. A. (2001), Amino acid residues involved in the coordination and assembly of the manganese cluster of photosystem II. Proton-coupled electron transport of the redox-active tyrosines and its relationship to water oxidation. Biochim. Biophys. Acta 1503, 147-163.

Ghirardi M. L., Preston C. and Seibert M. (1998), Use of a novel histidyl modifier to probe for residues on tris-treated photosystem II membrane fragments that may bind functional manganese. Biochemistry 37, 13567-13574.

Johnson G. N., Rutherford A. W. and Krieger A. (1995), A change in the midpoint potential of the quinone $\mathrm{Q}_{\mathrm{A}}$ in photosystem II associated with photoactivation 
of oxygen evolution. Biochim. Biophys. Acta 1229, 202- 207.

Kamachi H., Tamura N. Yoshihira T. and Oku T. (1994), Photoactivation of the latent water-oxidizing complex in photosystem II membranes isolated from darkgrown spruce seedlings. Physiol. Plant. 91, 747-753.

Klimov V. V., Dolan E., Shaw E. R. and Ke B. (1980), Interaction between the intermediary electron acceptor (pheophytin) and a possible plastoquinone-iron complex in photosystem II reaction centers. Proc. Natl. Acad. Sci. USA 77, 7227-7231.

Klimov V. V., Allakhverdiev S. I., Shuvalov V. A. and Krasnovsky A. A. (1982), Effect of extraction and readdition of manganese on light reactions of photosystem-II preparations. FEBS. Lett. 148, 307-312.

Lavorel J. and Seibert M. (1982), Patterns of oxygen emission from active oxygen-evolving photosystem II particles subjected to sequences of flashes. FEBS Lett. 144, $101-103$.

Law N. A., Caudle T. and Pecoraro V. L. (1999), Manganese redox enzymes and model systems: properties, structures, and reactivity. Adv. Inorg. Chem. 46, $305-440$.

Magnuson A., Rova M., Mamedov F., Fredriksson P.-O. and Styring S. (1999), The role of cytochrome $b_{559}$ and tyrosine $_{\mathrm{D}}$ in protection against photoinhibition during in vivo photoactivation of photosystem II. Biochim. Biophys. Acta 1141, 180-191.

Miller A.-F. and Brudvig G. W. (1990), Electron-transfer events leading to reconstitution of oxygen-evolution activity in manganese-Depleted photosystem II membranes. Biochemistry 29, 1385-1392.

Miyao M. and Inoue Y. (1991a), Enhancement by chloride ions of photoactivation of oxygen evolution in manganese-depleted photosystem II membranes. Biochemistry 30, 5379-5387.

Miyao M. and Inoue Y. (1991b), An improved procedure for photoactivation of photosynthetic oxygen evolution: Effect of artificial electron acceptors on the photoactivation yield of $\mathrm{NH}_{2} \mathrm{OH}$-treated wheat Photosystem II membranes. Biochim. Biophys. Acta 1056, $47-56$.

Nugent J. H. A., Rich A. M. and Evans M. C. W. (2001), Photosynthetic water oxidation: towards a mechanism. Biochim. Biophys. Acta 1503, 138-146.

Ono T.-A. and Inoue Y. (1991), Biochemical evidence for histidine oxidation in photosystem II depleted of the Mn-cluster for $\mathrm{O}_{2}$-evolution. FEBS Lett. 278, $183-186$.

Padhye S. B., Rane S. Y. and Gupta S. G. (1978), Manganese(II) chelates of naturally occurring vitamin $\mathrm{K}$ artefacts. Inorg. Nucl. Chem. Lett. 14, 83-86.

Reddy K. R., Rajasekharan M. V., Arulsamy N. and Hodgson J. (1996), Synthesis and structural investigations of $\left[\mathrm{Mn}_{3} \mathrm{O}_{4}(\text { phen })_{4}\left(\mathrm{H}_{2} \mathrm{O}\right)_{2}\right]\left(\mathrm{NO}_{3}\right)_{4} \cdot 2.5 \mathrm{H}_{2} \mathrm{O}: \mathrm{A}$ water-bound complex obtained by cerium(IV) oxidation. Inorg. Chem. 35, 2283-2286.
Renger G. (2001), Photosynthetic water oxidation to molecular oxygen: apparatus and mechanism. Biochim. Biophys. Acta 1503, 210-228.

Robblee J. H., Cinco R. M. and Yachandra V. K. (2001), $\mathrm{X}$-ray spectroscopy-based structure of photosynthetic oxygen evolution. Biochim. Biophys. Acta 1503, 7-23.

Rova M., McEwen B., Fredriksson P.-O. and Styring S. (1996), Photoactivation and photoinhibition are competing in a mutant of Chlamydomonas reinhardtii lacking the $23-\mathrm{kDa}$ extrinsic subunit of photosystem II. J. Biol. Chem. 271, 28918-28924.

Saygin Ö. and Witt H. T. (1987), Optical characterization of intermediates in the water-splitting enzyme system of photosynthesis - possible states and configurations of manganese and water. Biochim. Biophys. Acta 893, $452-469$.

Schäfer K.-O., Bittl R., Zweygart W., Lendzian F., Haselhorst G., Weyhermüller T., Wieghardt K. and Lubitz W. (1998), Electronic structure of antiferromagnetically coupled dinuclear manganese $\left(\mathrm{Mn}^{\mathrm{III}} \mathrm{Mn}^{\mathrm{IV}}\right)$ complexes studied by magnetic resonance techniques. J. Am. Chem. Soc. 120, 13104-13120.

Tamura N. and Cheniae G. (1987), Photoactivation of the water-oxidizing complex in photosystem II membranes depleted of $\mathrm{Mn}$ and extrinsic proteins. I. Biochemical and kinetic characterization. Biochim. Biophys. Acta 890, 179-194.

Tamura N., Inoue Y. and Cheniae G. M. (1989), Photoactivation of the water-oxidizing complex in Photosystem II membranes depleted of $\mathrm{Mn}, \mathrm{Ca}$ and extrinsic proteins. II. Studies on the functions of $\mathrm{Ca}^{2+}$. Biochim. Biophys. Acta 976, 173-181.

Theil S., Yerande R., Chikate R., Dahan F., Bousseksou A., Padhye S. and Tuchagues J.-P. (1997), Synthesis, structure, and magnetic and redox properties of linear bis-dinuclear complexes afforded by Schiff base ligands containing catecholate and pyridine or imidazole groups. Inorg. Chem. 36, 6279-6286.

Vass I. and Inoue Y. (1992), Thermoluminescence in the study of photosystem II. In: The Photosystems: Structure, Function and Molecular Biology (J. Barber, ed.). Elsevier, Amsterdam, pp. 259-294.

Völker M. Ono T., Inoue Y. and Renger G. (1985), Effect of trypsin on PS-II particles. Correlation between Hill-activity, Mn-abundance and peptide pattern. Biochim. Biophys. Acta 806, 25-34.

Wells W., Harton A. and Vincent J. B. (1993), Ultraviolet difference absorbance spectra of oxo-bridged manganese complexes: relationship to the photosynthetic Mn and Mn catalase. Biochim. Biophys. Acta 1144, $346-352$.

Wieghardt K. (1989), The active sites in manganese-containing metalloproteins and inorganic model complexes. Angew. Chem. Eng. 28, 1153-1172. 